\title{
A versatile lab-on-a-chip tool for modeling biological barriers
}

\author{
Fruzsina R. Walter ${ }^{1}$, Sándor Valkai ${ }^{1}$, András Kincses, András Petneházi, Tamás Czeller, \\ Szilvia Veszelka, Pál Ormos, Mária A. Deli*, András Dér*
}

Institute of Biophysics, Biological Research Centre, Hungarian Academy of Sciences, Temesvári krt. 62, H-6726 Szeged, Hungary

\section{A R T I C L E I N F O}

\section{Article history:}

Received 13 April 2015

Received in revised form 24 July 2015

Accepted 28 July 2015

Available online xxx

\section{Keywords:}

Microfluidics

Lung and intestinal epithelial cells

Endothelial cells

Blood-brain barrier

Permeability

Trans-epithelial/endothelial electric resistance

\begin{abstract}
A B S T R A C T
Models of biological barriers are important to study physiological functions, transport mechanisms, drug delivery and pathologies. However, there are only a few integrated biochips which are able to monitor several of the crucial parameters of cell-culture-based barrier models. The aim of this study was to design and manufacture a simple but versatile device, which allows a complex investigation of barrier functions. The following functions and measurements are enabled simultaneously: co-culture of 2 or 3 types of cells; flow of culture medium; visualization of the entire cell layer by microscopy; real-time transcellular electrical resistance monitoring; permeability measurements. To this end, a poly(dimethylsiloxane)-based biochip with integrated transparent gold electrodes and with a possibility to connect to a peristaltic pump was built. Unlike previous systems, the structure of the device allowed a constant visual observation of cell growth over the whole membrane surface. Morphological characterization of the layers was also accomplished by immunohistochemical staining. The chip was applied to monitor and characterize models of the intestinal and lung epithelial barriers, and the blood-brain barrier. The models were established using human Caco-2 intestinal and A549 lung epithelial cell lines, hCMEC/D3 human brain endothelial cell line and primary rat brain endothelial cells co-cultured with primary astrocytes and brain pericytes. This triple primary co-culture blood-brain barrier model was assembled on a lab-on-a-chip device and investigated under fluid flow for the first time. Such a versatile tool is expected to facilitate the kinetic investigation of various biological barriers.
\end{abstract}

(c) 2015 Elsevier B.V. All rights reserved.

\section{Introduction}

Epithelial outer, and endothelial inner barriers of the body are important defense systems to maintain homeostasis and play a crucial role in drug absorption and transport [1]. Culture models of biological barriers are important tools to study physiological functions, transport mechanisms, drug delivery and pathological processes [2]. Tight intercellular junctions are fundamental

Abbreviations: A549, human alveolar type II like lung epithelial cell line; BBB, blood-brain barrier; BSA, bovine serum albumin; Caco-2, intestinal colon carcinoma derived epithelial cell line; DMEM, Dulbecco's modified Eagle medium; EBA, Evans blue-labeled albumin; FBS, fetal bovine serum; FD, FITC-dextran $4.4 \mathrm{kDa}$; bFGF, basic fibroblast growth factor; GFAP, glial fibrillary acidic protein; hCMEC/D3, human brain microvascular endothelial cell line; ITO, indium tin oxide electrode; $P_{\text {app }}$, apparent permeability coefficient; PBS, phosphate buffered saline; PDMS, poly(dimethylsiloxane); SF, sodium fluorescein; $\alpha$-SM, $\alpha$-smooth muscle actin; TEER, transendothelial/epithelial electrical resistance (TEER).

* Corresponding authors.

E-mail addresses: deli.maria@brc.mta.hu (M.A. Deli), der.andras@brc.mta.hu (A. Dér).

1 These authors contributed equally to this manuscript. features of epithelial and endothelial barriers in vivo which are reflected in high electrical resistance and low passive permeability for hydrophilic compounds [1,2]. Cell culture inserts with porous membrane were introduced to measure these parameters on in vitro models in the 1980s. Confluent monolayers of adherent epithelial or endothelial cells grown on culture inserts are widely used static models for intestinal, lung and blood-brain barriers (BBB). The Caco-2 human epithelial cell line is a well characterized model of the intestinal barrier applied for screening of drug candidates [3-6]. Several studies describe the lung epithelial cell line A549 as a model of the lung barrier [7,8]. Culture-based BBB models greatly differ in complexity. Immortalized cell lines and mono-cultures of brain endothelial cells can be used as simplified BBB models [9-11], but the barrier properties of primary cell-based co-culture models are better $[2,12,13]$. We established a syngeneic rat BBB model based on the co-culture of primary brain endothelial cells with pericytes and glial cells mimicking the in vivo anatomical position of the cells. This triple co-culture BBB model displays barrier properties and in drug permeability assays shows good correlation with in vivo BBB permeability data [14,15].

Microtechnology and new lab-on-chip devices with integrated functions offer the possibility to study the barriers real-time, and 


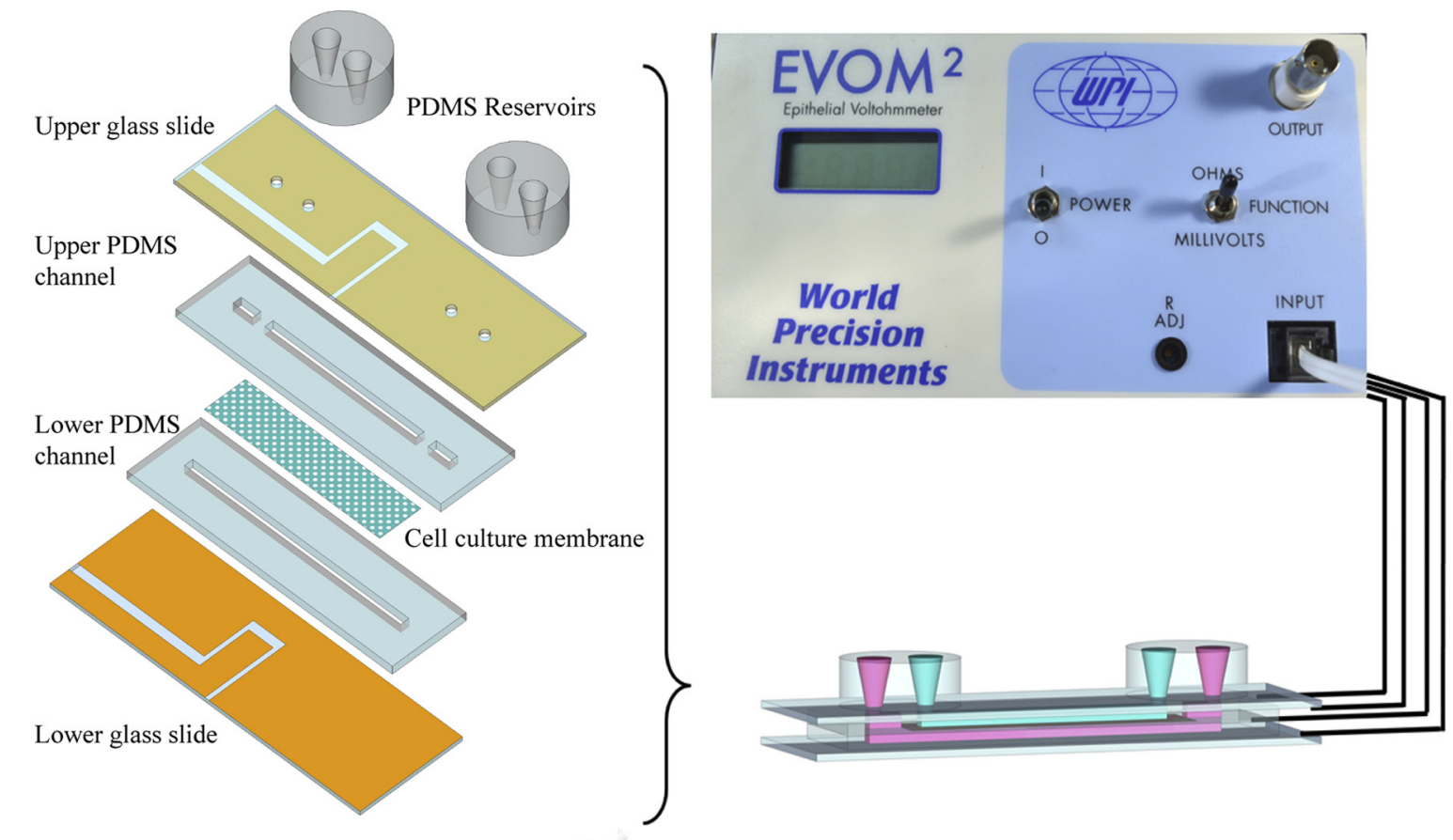

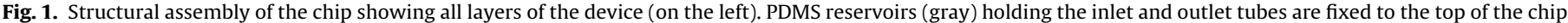

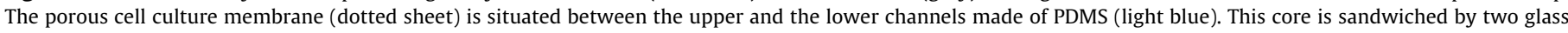

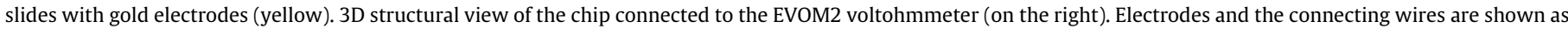
black lines.

under more physiological conditions [16,17]. In contrast to the static culture inserts, the cells can be exposed to fluid flow and shear stress, which are especially important for the vascular endothelium [18-20]. Although a dynamic BBB model on a 3-dimensional tube structure with a continuous flow of culture medium has been published, the real-time visualization of the cells is not possible with the hollow fiber system [18,21].

The aim of this study was to design and manufacture a versatile microdevice, which enables the co-culture of 2 or 3 cell types, the flow of the culture medium, visualization of the cells by microscopy, monitoring of the transcellular electrical resistance, and the measurement of monolayer permeability. An integrated lab-on-a-chip measuring chamber was built and applied to monitor and characterize four different barrier models. The chip proved to be suitable for the complex characterization of Caco-2 human intestinal and A549 human lung epithelial cell lines, hCMEC/D3 human brain endothelial cell line and primary rat brain endothelial cells cocultured with primary astrocytes and brain pericytes.

\section{Materials and methods}

\subsection{Ethics statement}

All animal studies were done according to the 1998. XXVIII. Hungarian law and the EU Directive 2010/63/EU about animal protection and welfare. Approval for animal studies was obtained from the local animal health authority, the Governmental Office for Csongrád County, Directorate of Food Chain Safety and Animal Health (Permit number: XVI./834/2012).

\subsection{Materials}

All reagents were purchased from Sigma-Aldrich Ltd., Hungary, unless otherwise indicated.

\subsection{Microfabrication process}

The barrier chip device, which is a two-layered, porous membrane based model, was fabricated using poly(dimethylsiloxane) (PDMS, Sylgard 184, Dow Corning GmbH, Germany). Dimensions for the top channel were $3.7 \mathrm{~cm} \times 0.2 \mathrm{~cm} \times 0.2 \mathrm{~cm}$, while the bottom channel was $4.2 \mathrm{~cm}$ long with the same diameter and height. For the chip parts, a 1:10 mixture of initiator and base material (silicone elastomer) was used, mixed and degassed by vacuum. After this step the material was poured on brass molds defining the shape of the channels. On the filled molds PDMS was cured at $75{ }^{\circ} \mathrm{C}$ on a hot plate for $30 \mathrm{~min}$ to achieve structural rigidity. To enable the composition of the model, the PDMS surfaces had to be treated with oxygen plasma. The plasma cleaner (PDC-002, Harrick Plasma, USA) and its chamber were evacuated to 150 mtorr, then a constant 400 mtorr pressure was set by excess oxygen. Having the oxygen pressure been stabilized, oxygen plasma was induced in the chamber by RF excitation ( $13.56 \mathrm{MHz}, 29.6 \mathrm{~W})$ for $30 \mathrm{~s}$. The treated upper and lower PDMS parts became highly adhesive and ready to assemble the microfluidic channels. A porous membrane (It4ip, Belgium; PET, thickness: $23 \mu \mathrm{m}$, pore size $0.45 \mu \mathrm{m}$, pore density $2 \times 10^{6} / \mathrm{cm}^{2}$ ) was used for separating the upper and lower channels. During the biochip fabrication process several membrane types were tested for cell cultivation (Fig. S1). Only one type of membrane from it4ip proved to be suitable for cell culture (Fig. S1). This membrane, receiving the same treatment as the PDMS components, was mechanically sandwiched between the oxygen plasma treated PMDS parts at its circumference as shown in Fig. 1. There was no surface reaction between these two materials, the oxygen plasma treated PDMS had a poor adhesion to the PET membrane. There is a small area ( $2 \mathrm{~mm} \times 2 \mathrm{~mm}$, Fig. 1$)$ where the adhesion between the PET membrane and the PDMS for perfect sealing was provided by a droplet of a silicone sealant adhesive (Aquarium RTV Silicone Sealant, Adarsha Specialty Chemicals Pvt. Ltd., India). This sealant adhesive has a relatively high viscosity so it can be applied precisely 
while it is soft for about $15 \mathrm{~min}$. It reaches the fully cross linked, solid state in $24 \mathrm{~h}$. The oxygen treated PDMS does not bond very well to metal surfaces either, so the microscope slides with gold electrodes were fixed to the PDMS with the same sealant adhesive. The sealant was applied as a thin, continuous line on the surface of the PDMS. The fabrication procedure was monitored under a stereo microscope. In the end, we had a $0.1 \mathrm{~mm}$ thick sealant layer that provided a good adhesion for the glass slides and sealed well both channels. PDMS blocks holding the inlet and outlet tubes (PCR tubes, Eppendorf, Germany) were fixed to the upper glass surface after plasma treatment. These parts served as medium reservoirs for the cell cultivation period (when flow was not applied). Four holes were drilled across the top glass slide for medium transport. Drilling was performed using a $1.5 \mathrm{~mm}$ diamond core drilling bit (Eternal Tools, UK) and a commercial drilling machine with some droplet of water added on the glass surface as coolant liquid at the spot of the hole.

Cell culture medium flow was driven by a peristaltic pump (Masterflex, Cole-Parmer) through silicone tubing ( $1 \mathrm{~mm}$ inner, $3 \mathrm{~mm}$ outer diameter, Carl Roth, Germany). The input tube was connected to the inlet of the chip, while the output tube was connected to the reservoir via the peristaltic pump. For all flow experiments low-shear-stress conditions ( $0.15 \mathrm{dyn}$ ) were used.

For the resistance measurements, a pair of 25-nm thick, transparent, gold electrodes was formed on each glass slide using sputter-coating (sputtering machine: K975X, EMITEC, France). The exact dimensions of the glass slides were $26 \times 76^{\circ} \mathrm{mm}$ (MenzelGlaser, Germany). Thin copper wires were glued to the gold electrodes with conductive epoxy drops (CW2400, ITW Chemtronics, USA) in order to connect them with the 4-channel input of the voltohmmeter (EVOM, World Precision Instruments, USA). For comparison to the common indium tin oxide (ITO) electrodes, we performed a recording of impedance spectra in the chip with transparent gold $(\mathrm{Au})$ and ITO electrodes. A voltage source (sinus function generator, TE $8020,20 \mathrm{MHz}$ ), the sample using one electrode on the top and one on the bottom plate of the chip and a reference resistance $(100 \Omega)$ were switched in series, and the voltage drop on the resistance was registered by a storage oscilloscope (LeCroy Wave Runner 6010A), from which the sample resistance values were calculated at different frequencies. The frequency range span from $1 \mathrm{~Hz}$ to $20 \mathrm{MHz}$, with 3 records in each decade. Prior to the measurements both of the channels were filled up with the same buffer as used in the cell culture experiments. Transmission spectra of gold and ITO electrodes was also evaluated (see Supplemetary material, Fig. S4).

The ready-to-use device was sterilized using $70 \%$ ethanol for $2 \mathrm{~h}$ then was washed with sterile distilled water 6 times, and the chip was treated with oxygen plasma again to turn the naturally hydrophobic PDMS surface hydrophilic.

\subsection{Cell cultures}

To test the versatility of the barrier chip, both epithelial and endothelial monolayers were cultured and monitored under static and flow conditions, as was appropriate. The transparent gold electrodes enabled a continuous visualization by phase contrast microscopy on the entire membrane surface. Cells were checked every day during the experiments. Visually confirmed leakage, holes on monolayers were accompanied by low TEER and resulted in the exclusion of the barrier chip from the experiments. Data were compared to measurements performed on Transwell cell culture inserts (Corning, USA). Cell cultures were grown in a humidified, $37^{\circ} \mathrm{C}$ incubator with $5 \% \mathrm{CO}_{2}$ in both experimental setups. A detailed description of the laboratory setup is available in the Supplementary material (Fig. S3).

\subsubsection{Epithelial cells}

Two human immortalized cell lines, Caco-2 intestinal epithelial cells and human alveolar type II like lung epithelial cells A549 (both from ATCC, USA) were cultured under static conditions to model epithelial barriers on the chip. A549 ( $\leq$ passage number 35) and vinblastine selected Caco-2 cells ( $\leq$ passage number 75 ; [22]) were cultured on rat tail collagen (prepared in the laboratory with acetic acid extraction) coated Petri dishes in Dulbecco's modified Eagle medium (DMEM, Biochrom, Germany) supplemented with $10 \%$ fetal bovine serum (FBS, Pan Biotech, Germany) and $50 \mu \mathrm{g} / \mathrm{ml}$ gentamicin. The porous membrane of the chip was coated with rat tail collagen overnight at $4{ }^{\circ} \mathrm{C}$. After cell cultures reached $80 \%$ confluency in the dishes, Caco- 2 cells $\left(7 \times 10^{4}\right.$ cells/chip) and A549 cells $\left(8 \times 10^{4}\right.$ cells/chip) were subcultured to the chip using $0.05 \%$ trypsin-EDTA solution (Pan Biotech, Germany). Confluent layers at maximal resistance were used for permeability measurements and immunolabeling. Cells were also cultured on Transwell inserts for resistance and permeability data comparison. Epithelial cells were passaged to inserts at a cell number of $8 \times 10^{4}$ cells/insert for A549 (insert: $1.12 \mathrm{~cm}^{2}, 0.4 \mu \mathrm{m}$ pore size, $4 \times 10^{6}$ pores $/ \mathrm{cm}^{2}$ ) and $10^{5}$ cells/insert for Caco- 2 cells (insert: $1.12 \mathrm{~cm}^{2}, 0.4 \mu \mathrm{m}$ pore size, $10^{8}$ pores $/ \mathrm{cm}^{2}$ ).

\subsubsection{Endothelial cells}

Brain microvascular endothelial cell line hCMEC/D3 [9] and primary rat brain endothelial cells [23-25] were used as models of the blood-brain barrier on the chip. Cultures of hCMEC/D3 cells ( $\leq$ passage number 35) were grown in MCDB 131 medium (Pan Biotech) supplemented with 5\% FBS, GlutaMAX (100×, Life Technologies, USA), lipid supplement $(100 \times$, Life Technologies, USA), $10 \mu \mathrm{g} / \mathrm{ml}$ ascorbic acid, $550 \mathrm{nM}$ hydrocortisone, $100 \mu \mathrm{g} / \mathrm{ml}$ heparin, $1 \mathrm{ng} / \mathrm{ml}$ basic fibroblast growth factor (bFGF, Roche, USA), insulin $(2.5 \mu \mathrm{g} / \mathrm{ml})$, transferrin $(2.5 \mu \mathrm{g} / \mathrm{ml})$, sodium selenite $(2.5 \mathrm{ng} / \mathrm{ml})$ and $50 \mu \mathrm{g} / \mathrm{ml}$ gentamicin. hCMEC/D3 brain endothelial cells $\left(6 \times 10^{4}\right.$ cells/chip) were seeded to microdevices similarly to epithelial cells. Static cultures were kept for 5 days before the permeability experiment. For flow studies cells were grown under static conditions until day 3 , and left 48 h under dynamic conditions before permeability studies. After the first day in culture both models received $10 \mathrm{mM}$ lithium chloride (Merck, USA) to induce barrier properties $[9,26,27]$. D3 cells were also subcultured to Transwell inserts $\left(1.12 \mathrm{~cm}^{2}, 0.4 \mu \mathrm{m}\right.$ pore size, $4 \times 10^{6}$ pores $\left./ \mathrm{cm}^{2}\right)$ at a cell number of $4 \times 10^{4}$ cells/insert.

Primary rat brain endothelial cells, pericytes and astroglia cells were isolated and cultured according to the method described in our previous studies $[22,23]$. To establish the triple culture model the upper compartment of the barrier chip was coated with rat tail collagen for endothelial cells and with collagen type IV for pericytes and glial cells overnight at $4{ }^{\circ} \mathrm{C}$. Pericytes at passage number $3\left(1.5 \times 10^{4}\right.$ cells/chip) were seeded to the bottom side of the porous membrane according to the method of Nakagawa et al. [14,15]. Primary glial cells $\left(10^{5}\right.$ cells/chip) were seeded to the bottom of the lower chamber directly to the coated glass surface. Primary rat brain endothelial cells $\left(7 \times 10^{4}\right.$ cells/chip) were passaged to the upper side of the coated membrane with endothelial culture medium: DMEM/F12 supplemented with plasma-derived bovine serum (15\%; First Link, UK), heparin $(100 \mu \mathrm{g} / \mathrm{ml})$, bFGF ( $1 \mathrm{ng} / \mathrm{ml}$; Roche, Switzerland), insulin $(5 \mu \mathrm{g} / \mathrm{ml})$, transferrin $(5 \mu \mathrm{g} / \mathrm{ml})$, sodium selenite $(5 \mathrm{ng} / \mathrm{ml})$ and gentamycin $(50 \mu \mathrm{g} / \mathrm{ml})$. Static co-cultures were kept for 6 days before the permeability experiment. For flow measurements, cultures were grown under static conditions until day 4 , and were kept for $48 \mathrm{~h}$ under dynamic conditions before permeability studies. After the second day in culture both models received $550 \mathrm{nM}$ hydrocortisone. One day before the static permeability test or the beginning 
A)

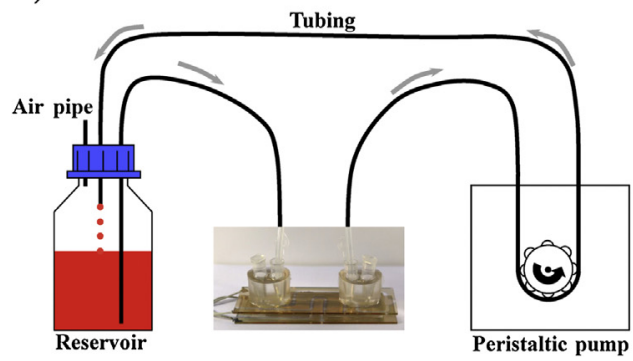

B)

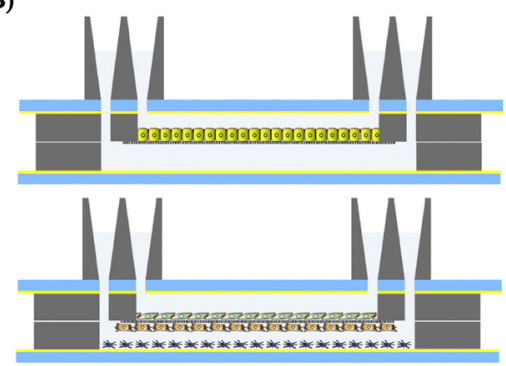

C)

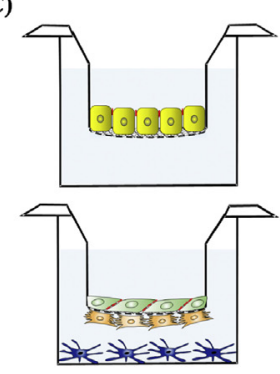

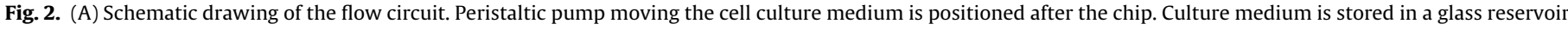

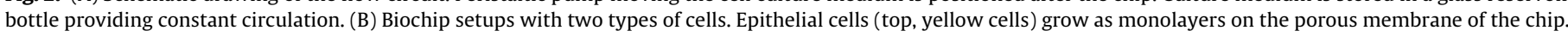

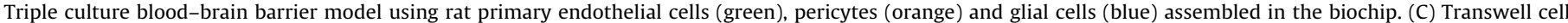
culture inserts with the same arrangements for epithelial or endothelial cell models as shown in the microchip.

of flow experiments cells were treated with chlorophenylthioadenosine-3',5'-cyclic monophosphate (250 $\mu \mathrm{M}$, CPT-cAMP) and RO 201724 (17.5 $\mu \mathrm{M}$, Roche) to tighten junctions and elevate resistance $[2,28]$. For comparison, cells were also kept on Transwell inserts $\left(1.12 \mathrm{~cm}^{2}, 0.4 \mu \mathrm{m}\right.$ pore size, $4 \times 10^{6}$ pores $\left./ \mathrm{cm}^{2}\right)$. Triple primary co-culture BBB model was assessed as shown in Fig. 2 and described previously $[15,24,29]$.

\subsection{Cell culture characterization}

Cells grown on the barrier chip received fresh culture medium every day. Transendothelial/epithelial electrical resistance (TEER) measurement was performed before every medium change, minimum once in every $24 \mathrm{~h}$. Under dynamic flow conditions no medium change was required, because the cell culture medium was moved continuously by the peristaltic pump positioned after the chip in the circuit. Permeability measurements as layer integrity tests and immunohistochemical labeling for morphological characterization were performed at the end of all experiments. Cells on Transwell inserts received fresh culture medium every second day. TEER was also measured according to culture protocols. After reaching appropriate TEER values permeability experiments were performed. These methods are accepted and widely used in the barrier field as integrity measurements and testing model applicability.

The flux of the hydrophilic tracers sodium fluorescein (SF, MW: $376 \mathrm{Da}$ ) and fluorescein isothiocyanate-labeled dextran (FD, MW: $4.4 \mathrm{kDa}$ ) indicating paracellular permeability was measured. Permeability of Evans blue-labeled albumin (EBA, MW: $67 \mathrm{kDa}$ ) was also tested across cell monolayers as previously described [24,25]. For the assay cell culture medium was changed in the lower compartment of the chip to $500 \mu \mathrm{l}$ Ringer-Hepes solution $(118 \mathrm{mM}$ $\mathrm{NaCl}, 4.8 \mathrm{mM} \mathrm{KCl}, 2.5 \mathrm{mM} \mathrm{CaCl}_{2}, 1.2 \mathrm{mM} \mathrm{MgSO}_{4}, 5.5 \mathrm{mM}$ D-glucose, $10 \mathrm{mM}$ Hepes, $\mathrm{pH}$ 7.4). In the upper compartment culture medium was replaced by $250 \mu$ l Ringer-Hepes solution containing either $10 \mu \mathrm{g} / \mathrm{ml} \mathrm{SF}$ or $100 \mu \mathrm{g} / \mathrm{ml} \mathrm{FD}$ and $165 \mu \mathrm{g} / \mathrm{ml}$ Evans blue bound to $1 \%$ bovine serum albumin (BSA) simultaneously. At 20,40 and 60 min of the permeability assay Ringer-Hepes solution in the lower compartment was changed to a fresh $500 \mu$ l buffer. Samples from the luminal and abluminal compartments were collected. Permeability measurements were also performed on Transwell inserts using $500 \mu \mathrm{l}$ volumes with marker molecules for the upper and $1500 \mu \mathrm{l}$ for the lower compartments [24,25]. During the experiments inserts were kept in 12-well plates (Corning, USA) and inserts were moved after 20, 40 and $60 \mathrm{~min}$ to the next well of the plate. Barrier chips and plates with inserts were incubated on a horizontal shaker in the $\mathrm{CO}_{2}$ incubator ( $100 \mathrm{rpm}$; Biosan, Latvia) at $37^{\circ} \mathrm{C}$ for $1 \mathrm{~h}$. SF and FD concentrations were determined by the same instrument using $485 \mathrm{~nm}$ excitation and $520 \mathrm{~nm}$ emission wavelengths. EBA content of samples was measured at $584 \mathrm{~nm}$ excitation and $680 \mathrm{~nm}$ emission wavelengths (Fluostar Optima, BMG Labtechnologies, Germany). Apparent permeability coefficient $\left(P_{\text {app }}\right)$ was calculated as described previously [3].

Morphological characterization of epithelial and endothelial cell lines grown in the barrier chip was investigated by immunohistochemical staining for $\mathrm{ZO}-1$ and $\beta$-catenin tight and adherens junction associated cytoplasmic linker proteins. In the triple co-culture model endothelial cells were stained for ZO- 1 and $\beta$ catenin, pericytes for $\alpha$-smooth muscle actin $(\alpha-S M)$ and astroglial cells for glial fibrillary acidic protein (GFAP). Before ZO-1 labeling double cell nucleus staining with ethidium homodimer-1 and bis-benzimide was performed to reveal cell death. After the permeability tests cells were fixed with cold acetone-methanol solution (1:1) for $10 \mathrm{~min}$, washed with phosphate buffered saline (PBS) and non-specific binding sites were blocked with 3\% BSA-PBS for $1 \mathrm{~h}$ at room temperature. Incubation with rabbit-anti-ZO-1, rabbit anti- $\beta$-catenin, mouse anti- $\alpha$-SM (Dako, USA) and mouseanti-GFAP primary antibodies lasted overnight at $4{ }^{\circ} \mathrm{C}$. Cells were incubated with anti-rabbit secondary antibody labeled with Cy3 or anti-mouse secondary antibody labeled with Alexa Fluor 488 (Life Technologies, USA) and H33343 dye to stain nuclei for $1 \mathrm{~h}$ at room temperature. Between incubations cells were washed three times with PBS. Chips were disassembled, cell culture membranes were removed from the chip and were mounted in Fluoromount-G (Southern Biotech, USA), except for astroglia which were photographed in situ in PBS. Stainings were visualized by a Leica TCS SP5 confocal laser scanning microscope (Leica Microsystems, Germany).

\subsection{Statistical analysis}

Data are presented as means \pm SD. Statistical significance between treatment groups was determined using two-way ANOVA following Bonferroni multiple comparison posttest (GraphPad Prism 5.0; GraphPad Software, USA). Changes were considered statistically significant at $p<0.05$ (a, compared to Transwell inserts and $b$, compared to static chip conditions). All experiments were repeated at least three times, the number of parallel samples was 3-5.

\section{Results and discussion}

\subsection{Chip structure and assembly}

The structure of the barrier chip was fabricated by bonding five layers including the bottom and top glass slides with the measuring electrodes, the upper and lower channels made of PDMS, and the porous membrane (Fig. 1). 


\section{Impedance spectra}

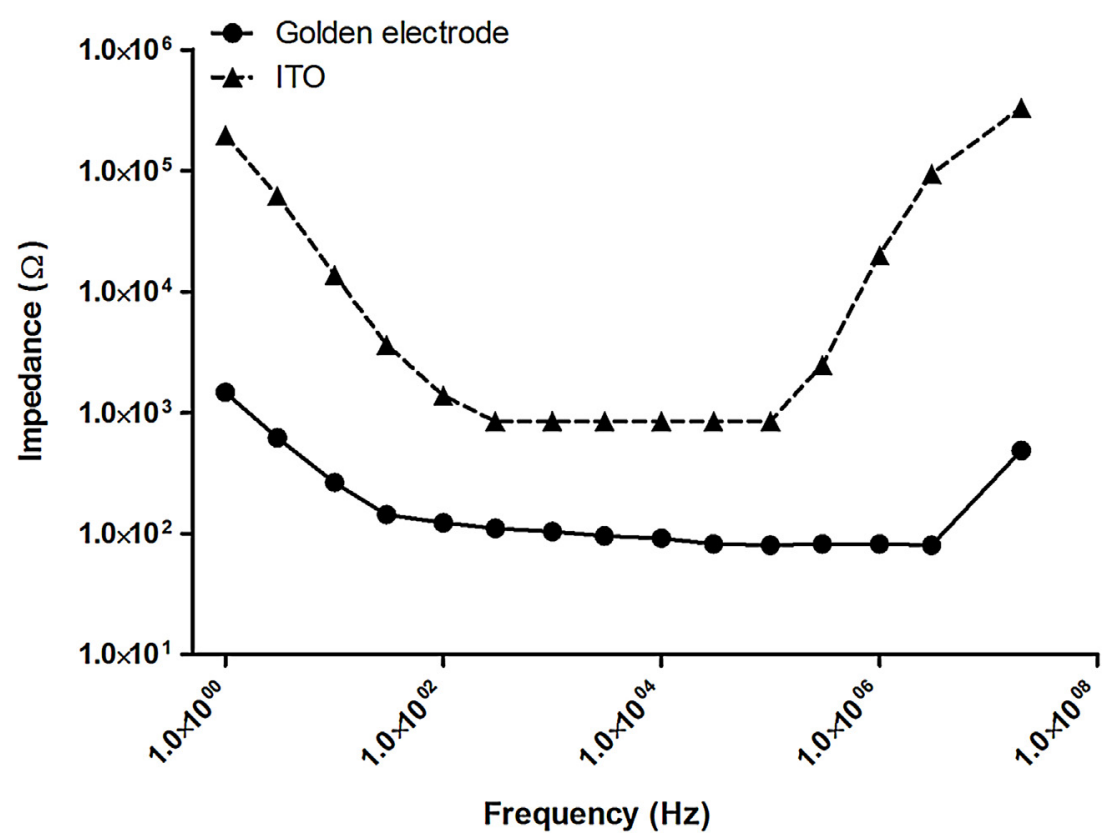

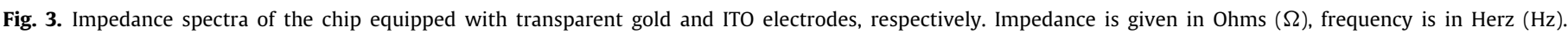
Measurements were performed between $1 \mathrm{~Hz}$ and $20 \mathrm{MHz}$.

There are several setups built for similar purposes. Most of them consist of two channels, either parallel [30] or perpendicular to each other [19,31], with a relatively small overlapping area. The arrangement of our channels enables a much larger overlapping area (ca. $1 \mathrm{~cm}^{2}$ ), allowing a larger surface and a bigger sampling size for in vitro permeability studies.

The thin, transparent electrodes grant a special advantage to the chip, permitting a continuous visual monitoring of the cells by a microscope, above the entire membrane surface, during the full time span of the experiment. Such a feature is missing in other model systems using nontransparent electrodes that allow visual observation limited to the narrow slits between the electrodes [16,19], therefore a full microscopic screening of the sample can only be done on the disassembled chip. This is a critical point for such assays that include monitoring of TEER or paracellular permeability of the barrier membrane, since local faults in the confluence of the cell layer, occurring usually at its perimeter and invisible for other methods, might seriously tamper the results.

We tested transparent ITO electrodes as possible candidates, and measured their resistance. Fig. 3 shows the impedance spectra of chips equipped either with a pair of transparent gold electrodes or ITO electrodes placed at the outer walls of the top and bottom channel, and separated by the porous membrane. In the low-frequency regime (between $1 \mathrm{~Hz}$ and $1 \mathrm{kHz}$ ) the electric double layer formed upon electrode polarization hinders the correct measurement of the ohmic resistance of the chip, and another dispersion process occurs in the $\mathrm{MHz}$ domain. In between the two extremes, the sample resistance is nearly constant, but its value is an order of magnitude smaller with gold electrodes than with the ITO ones. The high resistance of the latter (>800 Ohms) is comparable to or higher than typical TEER values of biological barriers, which might tamper the results of TEER measurements performed with ITO electrodes. This was the primary reason for which we used gold electrodes instead of ITO. Another problem was that proper electrode patterning with ITO glass was not feasible with our laboratory technique, therefore the standard four-electrode method, eliminating the effect of electrode polarization on TEER, could not be applied.

On the other hand, low-resistance "non-polarizable" electrodes (platinized platinum or $\mathrm{Ag}-\mathrm{AgCl}$ ) proved not to be transparent enough (extinction coefficient $>1$ ), hampering visual observation. The choice of a 25-nm inert, gold layer for TEER electrodes was found to be the best compromise between the opposing requirements of conductance and transparency $(10 \mathrm{Ohms}$, extinction coefficient 0.4, Fig. S4). Possible artifacts of the resistance measurements due to polarization of the gold electrodes were avoided by the four-electrode method. Rectangular pulses $(12.5 \mathrm{~Hz})$ were applied on the sample and kept controlled by a pair of electrodes, while another electrode pair was supplying load current via a feedback loop, to keep the transmembrane voltage constant during each half-period. The electric resistance of the system was found to be characteristic to the cell culture layer.

During the experiments, the medium was circulated by a peristaltic pump through silicone tubing (Fig. 2). PDMS blocks on the top serve both as reservoirs and in- or outlets for tubing. The input tube was immersed in the cell culture medium in the reservoir, and was connected to the inlet of the chip, while the output tube was connected to the reservoir via the peristaltic pump. This arrangement has three advantages: (i) the liquid pressure is always less than the air pressure outside, therefore there was no simmering or jamming failure (no "explosion"), (ii) the reservoir also acts as a bubble trap, since all bubbles (e.g. from leakages) burst as the liquid is dripping out from the output tube, and none of them can reach the input of the chip at the bottom of the reservoir, (iii) since the reservoir of the circulated medium is located after the pump, it is not pressurized, and the medium inside can be promptly and continuously sampled or treated very easily. That could be very useful for both long- and short-term tests of various drugs influencing the permeability of the barrier layer.

On the whole, the device enables several ways to study the barrier layer simultaneously: electric conductivity measurement, molecule permeability and microscopic visualization of the (co)cultured cells. In addition, morphological characterization of the 


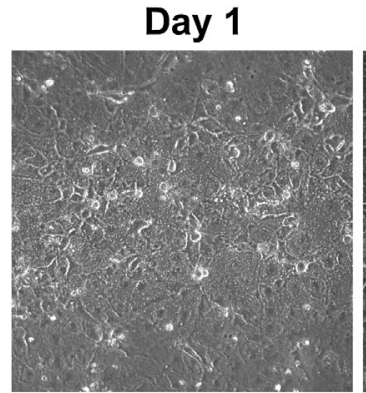

TEER

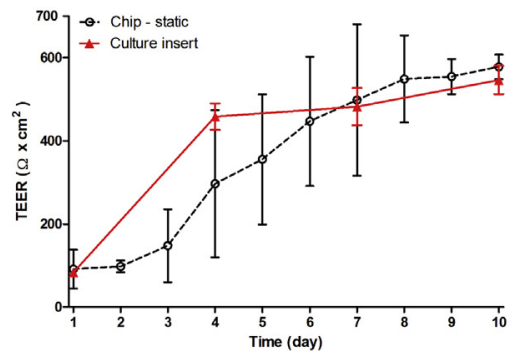

Day 3
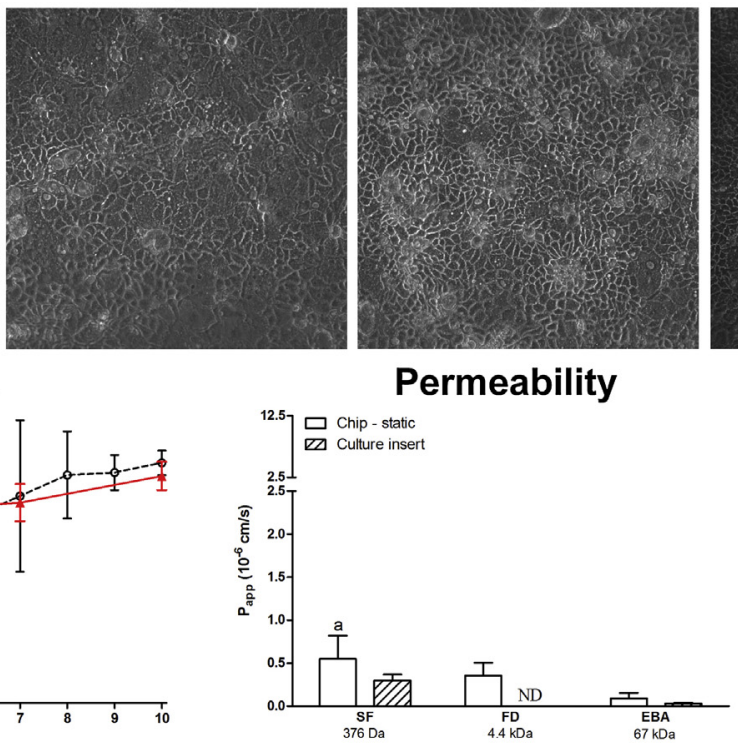

Day 7
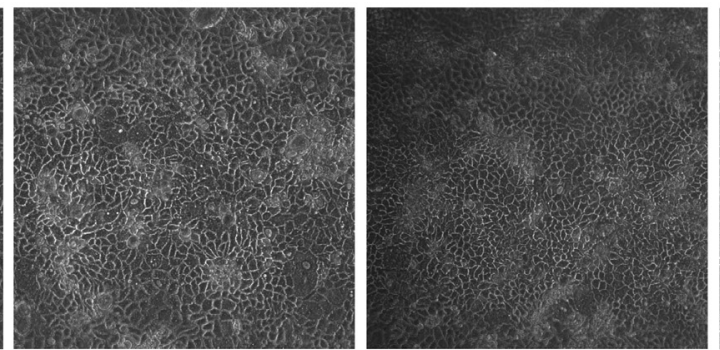

ZO-1

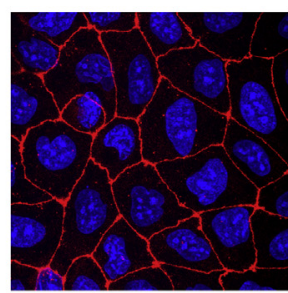

Day 10

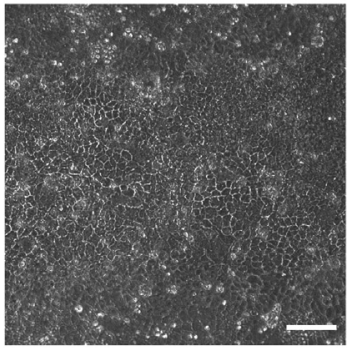

$\beta$-catenin

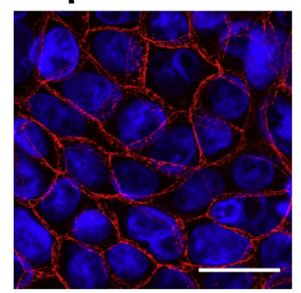

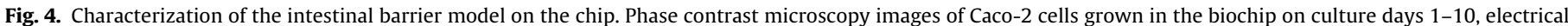

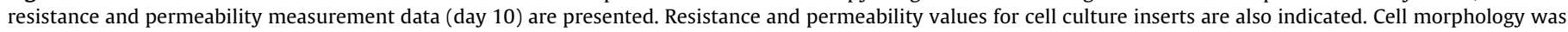

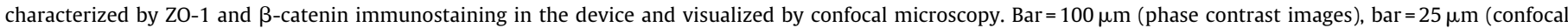
images), ND: no data available.

layers is also possible by immunohistochemical staining. The procedure we used to create the device is not for industrial mass production. The chip is a proof-of-concept device that can be modified according to various experimental requirements. A drawback of the system is that it can be used as a disposable piece, and is not yet optimized for large scale applications like drug screening. We plan to prepare plastic, reusable versions of the chip.

\subsection{Cell cultures}

In order to illustrate the main features of our integrated microdevice, it was used to model four different biological barriers with cell cultures: human intestinal epithelial, lung alveolar epithelial and brain endothelial cell lines as well as a triple primary co-culture BBB model were tested for barrier function in the chip.

\subsubsection{Intestinal model}

The Caco-2 intestinal epithelial cell line formed the tightest monolayer among the 4 models in the microdevice, with a TEER value of $578.3 \pm 29.6 \Omega \mathrm{cm}^{2}$ (Fig. 4). The tightness of the barrier was also indicated by the low $P_{\text {app }}$ for all markers (SF: $0.55 \times 10^{-6} \mathrm{~cm} / \mathrm{s}$; FD: $0.36 \times 10^{-6} \mathrm{~cm} / \mathrm{s}$; EBA: $0.10 \times 10^{-6} \mathrm{~cm} / \mathrm{s}$ ). Cells had a cuboidal shape, grew in monolayers and stained well for ZO- 1 and $\beta$-catenin. Cell morphology, good resistance and permeability properties of Caco- 2 cells in the new device were similar to data obtained on Transwell culture inserts after 10 days of culturing. On culture inserts, TEER of Caco- 2 monolayers reached $546.5 \pm 33.9 \Omega \mathrm{cm}^{2}$. There was a significant difference in the measured permeability for $\mathrm{SF}\left(0.30 \times 10^{-6} \mathrm{~cm} / \mathrm{s}\right)$ compared to the biochip, but permeability for $\operatorname{EBA}\left(0.03 \times 10^{-6} \mathrm{~cm} / \mathrm{s}\right)$ shows no difference between the insert and the chip setup. There was a higher standard deviation for TEER in biochips during the growing phase. Since it was not possible to use the same membrane type as for Transwell inserts (see Supplementary Material, Fig. S1), there could be a difference in the kinetics of cell growth due to the different culture membranes, but after cells reach confluency and begin to form the barrier, TEER values become more uniform between the parallels and reflect good barrier properties. Higher Lucifer yellow permeability has been described for the same cell type cultured in a microfluidic chamber, but that system did not allow measurement of TEER [30]. Note that Caco-2 cells in a gut-on-a-chip model have reached tighter barrier properties when co-cultured with bacteria and/or immune cells, and exposed to low shear stress and cyclic strain to mimic peristaltic motion $[4,32]$.

\subsubsection{Lung model}

Lung epithelial A549 cell line grew well on the chip and easily formed monolayers (Fig. 5). Compared to the case of Caco-2 cells, these monolayers represented a weaker epithelial barrier. Lung cell layers in the chip reached a maximum TEER of a $46.4 \pm 17.0 \Omega \mathrm{cm}^{2}$, and these values were in concordance with our data obtained on A549 culture on Transwell inserts $\left(27.8 \pm 2.2 \Omega \mathrm{cm}^{2}\right)$, as well as with literature data for this cell line [33]. Average $P_{\text {app }}$ values were $1.45 \times 10^{-6} \mathrm{~cm} / \mathrm{s}$ for SF, $1.24 \times 10^{-6} \mathrm{~cm} / \mathrm{s}$ for FD and $0.17 \times 10^{-6} \mathrm{~cm} / \mathrm{s}$ for EBA markers. No significant difference was found in the permeability values as compared to data measured on culture inserts $\left(P_{\mathrm{app}}: 0.9 \times 10^{-6} \mathrm{~cm} / \mathrm{s}\right.$ for FD and $0.3 \times 10^{-6} \mathrm{~cm} / \mathrm{s}$ for EBA). In accordance with the functional data, $\mathrm{ZO}-1$ and $\beta$-catenin staining was not as intensive and continuous as in Caco- 2 cells, indicating weaker intercellular junctions. Some lab-on-a-chip models using A549 cells [7,33,34] have already been published, but none of them offers simultaneous cell visualization, measurement of TEER and the flux of marker molecules. Concerning the lung model the chip will enable the establishment of a more complex model of the alveolar capillary unit, by the co-culture of lung epithelial cells with vascular endothelial cells at an air-liquid interface [35]. Modeling lung barriers in air-liquid interface condition is important and induces barrier properties. It is a limitation of the study that such conditions were not included.

\subsubsection{Blood-brain barrier models}

3.2.3.1. Brain endothelial cell line model. The human hCMEC/D3 brain endothelial cell line is a widely used, well-characterized and simplified in vitro model of the BBB [10]. Still, a comprehensive study on a human brain endothelial cell line in a microdevice, with a complex characterization of barrier properties including 
Day 1

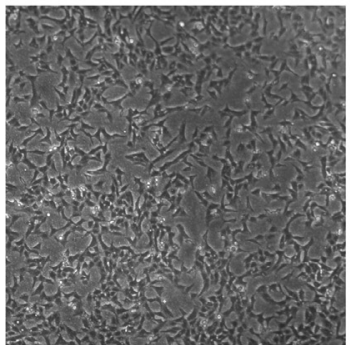

TEER

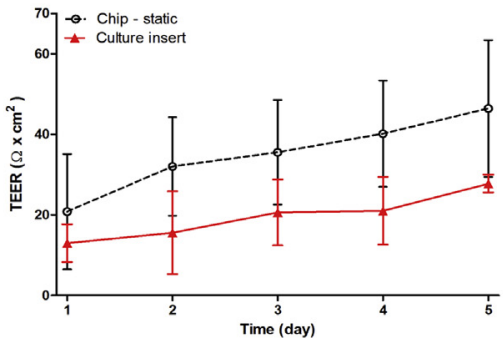

Day 2
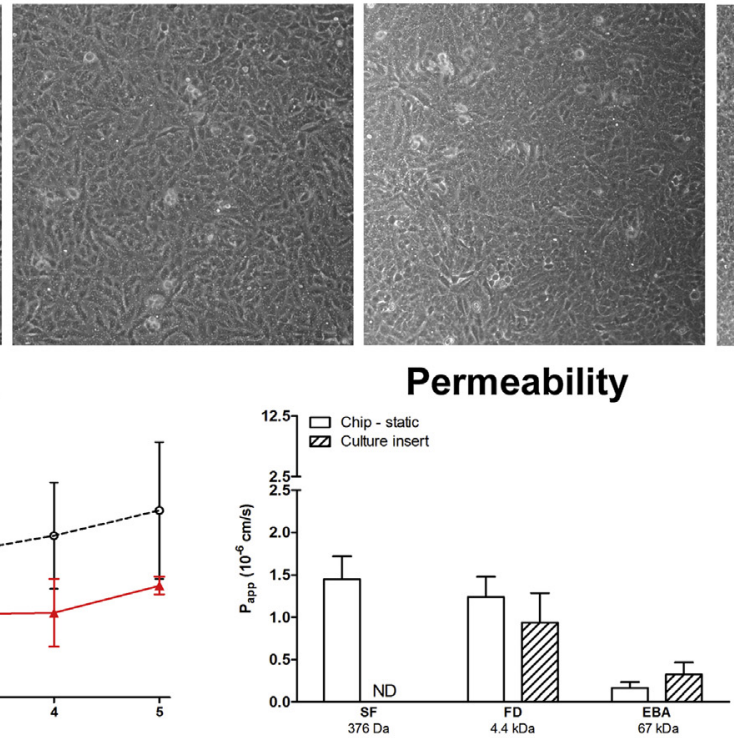

Day 4
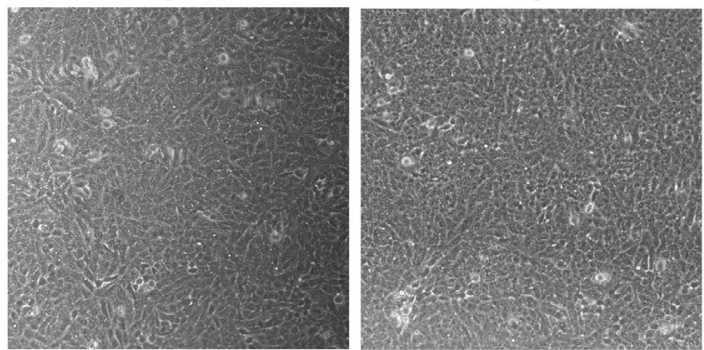

ZO-1

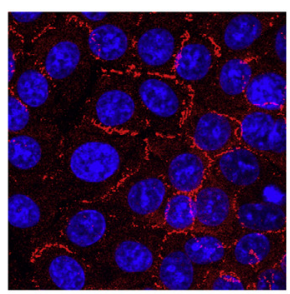

Day 5

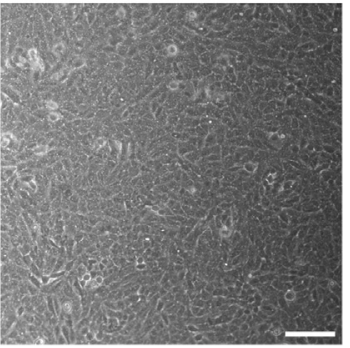

$\beta$-catenin

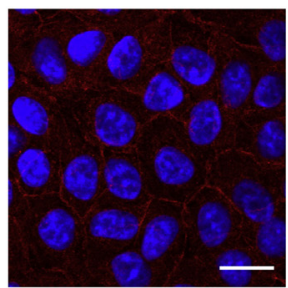

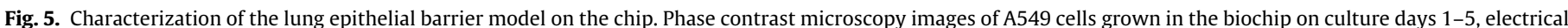

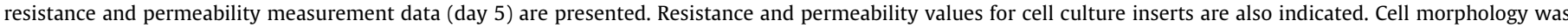

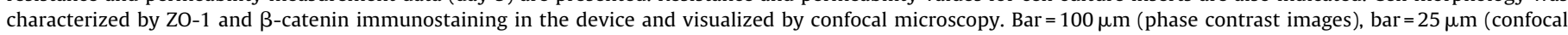
images), ND: no data available.

microscopy, has so far been missing. Previously, the rat cell line RBE4 was studied for a similar purpose [17,36]. Biochips modeling the vascular system also widely use peripheral endothelial cells [37-40].

In our miniaturized model, D3 cells grew to confluency (Fig. 6). After 3 days of static followed by 2 days of dynamic culture conditions, TEER values increased to $28.5 \pm 7.2 \Omega \mathrm{cm}^{2}$. TEER values of the 5 -day-old static culture were in the range of $19.0 \pm 2.8 \Omega \mathrm{cm}^{2}$. The resistance values measured by the device were in concert with the ones obtained on culture inserts by our group $\left(23.7 \pm 3.5 \Omega \mathrm{cm}^{2}\right)$, and with those described in the literature [10,31]. Permeability data were also compared between the static and dynamic cultures. On the static hCMEC/D3 barrier chip model, the permeability was $1.61 \times 10^{-6} \mathrm{~cm} / \mathrm{s}$ for $\mathrm{SF}, 1.55 \times 10^{-6} \mathrm{~cm} / \mathrm{s}$ for FD and $0.51 \times 10^{-6} \mathrm{~cm} / \mathrm{s}$ for EBA. Under dynamic culture conditions $P_{\text {app }}$ of $1.57 \times 10^{-6} \mathrm{~cm} / \mathrm{s}$ for SF, $1.32 \times 10^{-6} \mathrm{~cm} / \mathrm{s}$ for FD and
Day 1
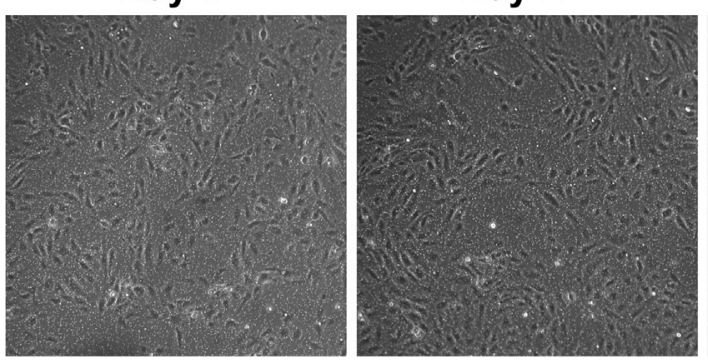

Day 3

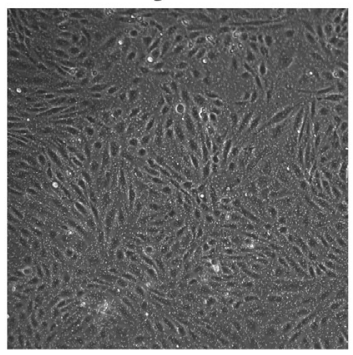

Permeability

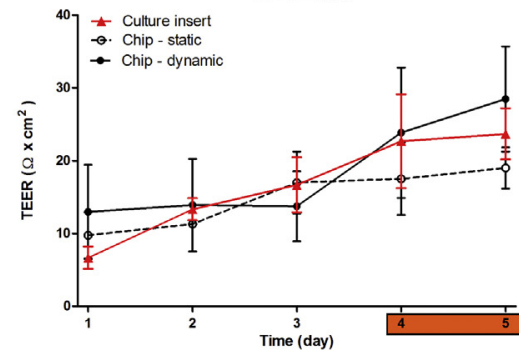

Day 4

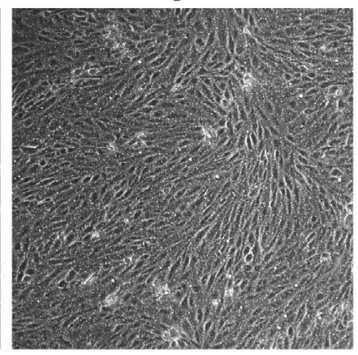

Day 5

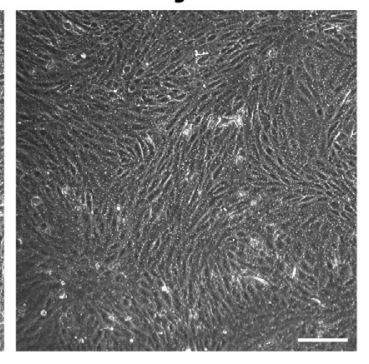

dynamic culture

ZO-1

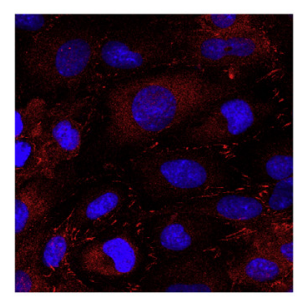

$\beta$-catenin

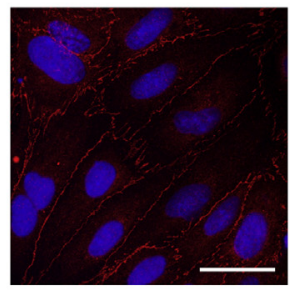

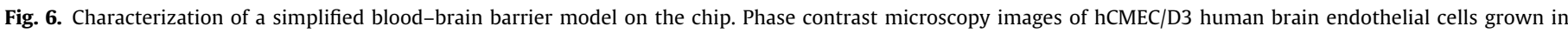

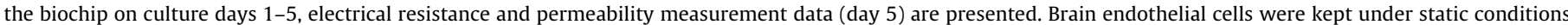

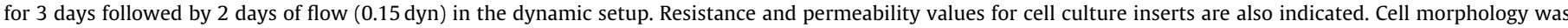

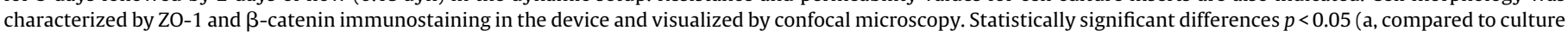
inserts; b, compared to static chip cultures) are indicated. Bar $=100 \mu \mathrm{m}$ (phase contrast images), bar $=25 \mu \mathrm{m}$ (confocal images). 
Astroglia

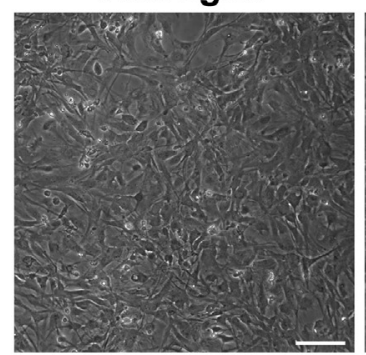

GFAP staining

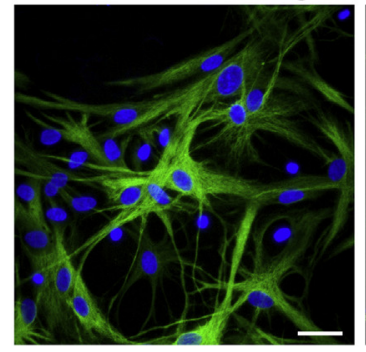

TEER

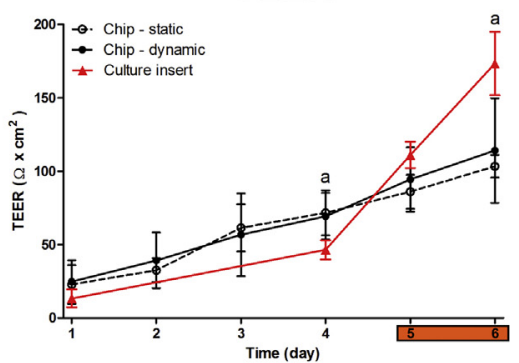

Pericyte

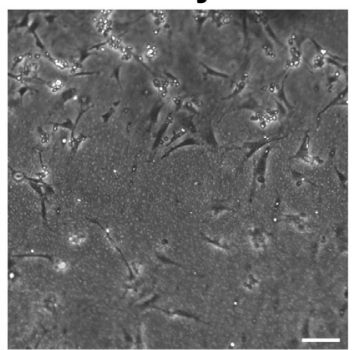

a-SM staining

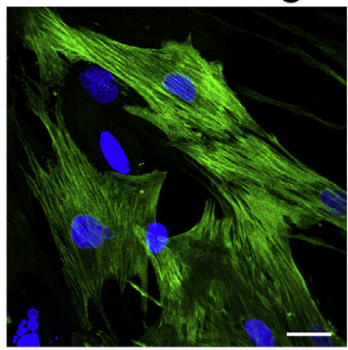

Day 1

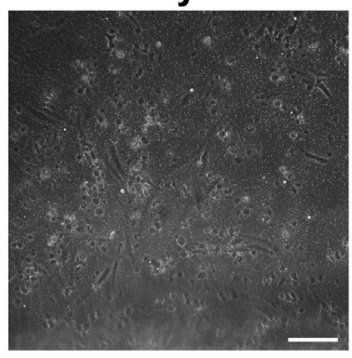

Day 4

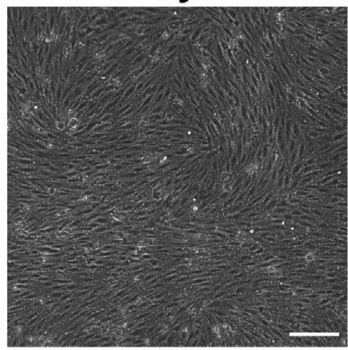

Permeability

Endothelial cell

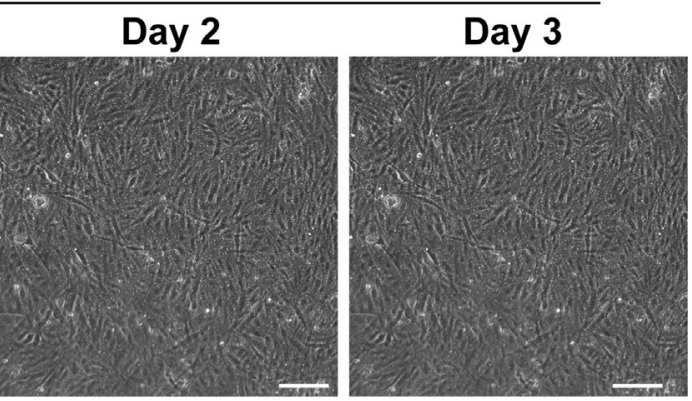

Day 5

Day 6
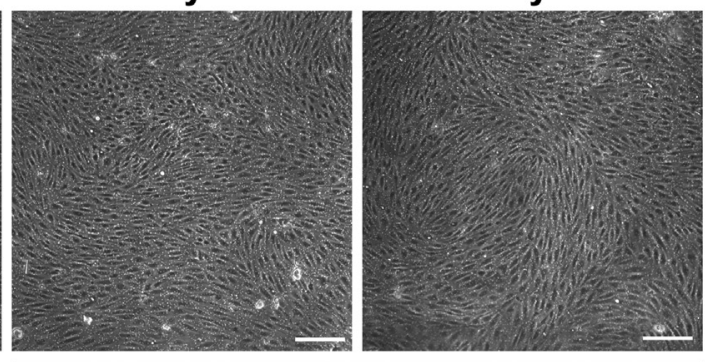

dynamic culture

ZO-1

$\beta$-catenin
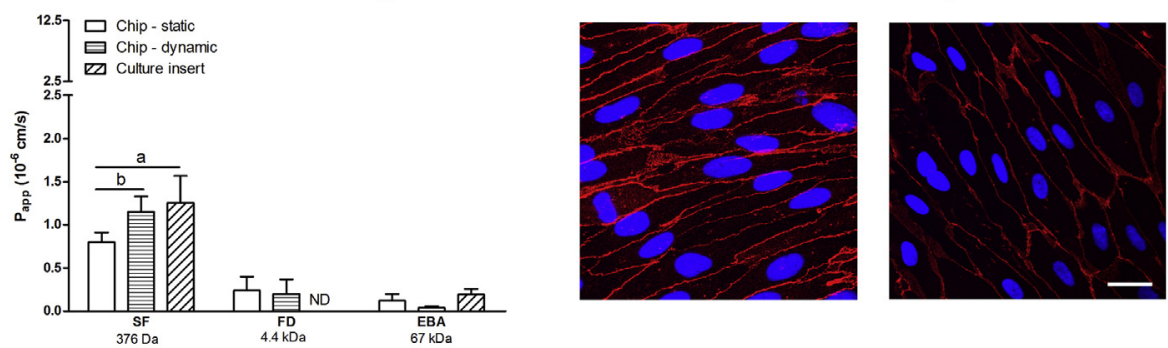

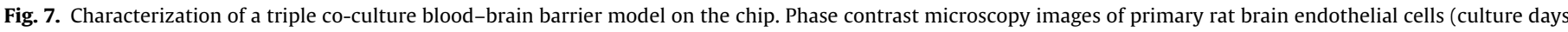

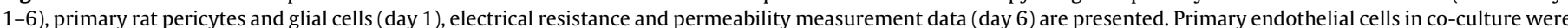

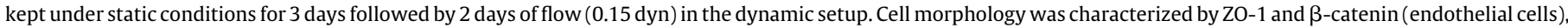

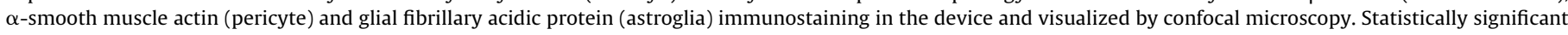

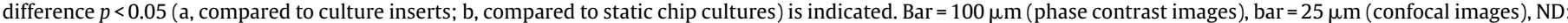
no data available.

$0.15 \times 10^{-6} \mathrm{~cm} / \mathrm{s}$ for EBA was measured. In dynamic cultures, brain endothelial permeability for FD and EBA markers was significantly lower compared to the static model in the same device. Permeability data obtained on Transwell inserts $\left(9.31 \times 10^{-6} \mathrm{~cm} / \mathrm{s}\right.$ for $\mathrm{SF}, 5.47 \times 10^{-6} \mathrm{~cm} / \mathrm{s}$ for FD and $0.87 \times 10^{-6} \mathrm{~cm} / \mathrm{s}$ for EBA) are in good correlation with the literature [9], but those measured in the biochip were found to be significantly lower for all marker molecules. Since we could not use the exactly same membrane type in both the Transwell and chip models as explained in the Supplementary material (Fig. S1), the effect of membrane thickness on permeability coefficients cannot be excluded. In the present study we could not reproduce the intensive increase in resistance after exposing hCMEC/D3 to shear stress [31,41], but we could observe a significantly reduced tracer permeability for larger marker molecules, indicating a barrier-tightening effect. Cells in both dynamic and static cultures were elongated, formed close contacts typical for endothelial monolayers, and stained well for ZO-1 and $\beta$-catenin (Fig. 6).

3.2.3.2. Primary cell based co-culture model of the $B B B$. Our primarycell-based triple co-culture BBB model [15] was characterized for the first time in a miniaturized flow chip device. Co-culture of brain endothelial cells with glial cells and pericytes on Transwell inserts in the anatomical position (Fig. 2) was the most efficient in the induction of barrier properties as described previously by our group [15]. Brain endothelial cells in this BBB model showed higher TEER and lower permeability values, and expressed higher levels of junctional proteins than in other triple or double cultures using different combinations of brain endothelial cells, glial cells and pericytes [15] highlighting the important and functional role of pericytes. In this model, brain endothelial cells are not directly contacting pericytes or glial cells (Fig. 2). In the Transwell inserts a membrane with $0.4 \mu \mathrm{m}$ pore size, $12 \mu \mathrm{m}$ thickness is used (Fig. S1). A membrane with a same pore size was used in the chip, which does not allow cell migration. Growth factors and other barrier property inducing molecules are secreted into the common cell culture medium enabling communication between the three cell types through the porous culture membrane.

Cell growth in the triple BBB model was followed by phase contrast microscopy. Immunolabeling showed a typical cell shape for all three kinds of cells (Fig. 7). Endothelial cells had an elongated shape, and formed tight intercellular connections. Pericytes and glial cells were also stained by their cellular marker proteins, $\alpha$-SM actin and GFAP. The rat primary triple co-culture BBB model on the chip formed a barrier with a TEER value of $114.2 \pm 35.7 \Omega \mathrm{cm}^{2}$. TEER values measured under static and dynamic conditions were not 
significantly different. These values are lower than data obtained on culture inserts $\left(173.3 \pm 21.6 \Omega \mathrm{cm}^{2}\right)$. Compared to the results of our previous papers the TEER of the present triple model on Transwell inserts was lower (173vs. $350 \Omega \times \mathrm{cm}^{2}$; [15]), but the permeability coefficient for fluorescein was better, $0.8 \times 10^{-6} \mathrm{~cm} / \mathrm{s}$ vs. $4 \times 10^{-6} \mathrm{~cm} / \mathrm{s}$ indicating a good barrier. In static conditions permeability values were $0.80 \times 10^{-6} \mathrm{~cm} / \mathrm{s}$ for $\mathrm{SF}, 0.24 \times 10^{-6} \mathrm{~cm} / \mathrm{s}$ for FD and $0.12 \times 10^{-6} \mathrm{~cm} / \mathrm{s}$ for EBA on the BBB model. These permeability coefficient values are similar to data of previously described BBB models on Transwell inserts [3] and indicate a tight barrier. Dynamic cultures were kept under flow conditions for $48 \mathrm{~h}$, then permeability measurements were performed. $P_{\text {app }}$ values for the dynamic model were $1.15 \times 10^{-6} \mathrm{~cm} / \mathrm{s}$ for $\mathrm{SF}, 0.20 \times 10^{-6} \mathrm{~cm} / \mathrm{s}$ for FD and $0.04 \times 10^{-6} \mathrm{~cm} / \mathrm{s}$ for EBA. An elevated flux of SF across the monolayer was found after introducing low shear stress on the triple model. The permeability for SF on the triple BBB model grown on cell culture inserts was higher compared to the static biochip model $\left(1.25 \times 10^{-6} \mathrm{~cm} / \mathrm{s}\right.$ for SF and $0.19 \times 10^{-6} \mathrm{~cm} / \mathrm{s}$ for EBA). There was no difference in the flux of the other two permeability markers after flow conditions, neither in the static chip compared to the dynamic model, nor in the chip models compared to the Transwell inserts. In our setup, the low-shear-stress exposure did not elevate the resistance of primary endothelial cells. All these data indicate that under low flow conditions, barrier properties typical for venules may develop in a BBB model [21]. The different biological response in a brain endothelial cell line as compared to primary cells emphasizes the difference between such models [42].

\subsection{General considerations and comparison with other biochips modeling biological barriers}

In the permeability assays Caco and primary brain endothelial cell based models which have the highest resistance, have the lowest permeability and the A549 and D3 models which present low resistance show high permeability for the markers (Figs. 4-7; Fig. S2), in agreement with literature data. All barrier models were tested with double cell nucleus staining to reveal cell death. No red staining for nuclei was observed, indicating viable and functioning cells both in the static and dynamic models.

While several barrier functions were monitored, some aspects of barrier functions in the present study were not investigated. Mucus layers are present and important for intestinal and lung barriers including drug absorption [43]. In a recent three-dimensional model mimicking the microenvironment of the small intestine transport properties closer to the in vivo situation were measured [44]. At the blood-brain barrier the luminal surface of brain endothelium is covered by a relatively thick layer of glycocalyx which also acts as a physicochemical barrier blocking drug delivery [45]. We aim to further develop the culture models to study these more complex interactions. Culture models of barriers on planar surfaces represent simplified systems, where imaging, measurement of resistance, or drug transport studies are easier. However there are models using 3D scaffold which represent more complex systems mimicking the anatomical position of cells, for example a culture model of the small intestine [44].

The field of biochips modeling gut, lung and blood-brain barriers is rapidly evolving and several models were developed in the last ten years which are listed in Table 1. These complex biochips integrate different types of imaging, microfluidics, measurement of resistance in mono- and co-culture systems. To our best knowledge the present paper is the first in which the same device is used for three different types of barrier models, resistance is measured by transparent gold electrodes, and cellular growth can be monitored through the whole length of the device, not only through a small window. The triple cell culture model of the BBB we described on Transwell inserts was also investigated for the first time in a biochip

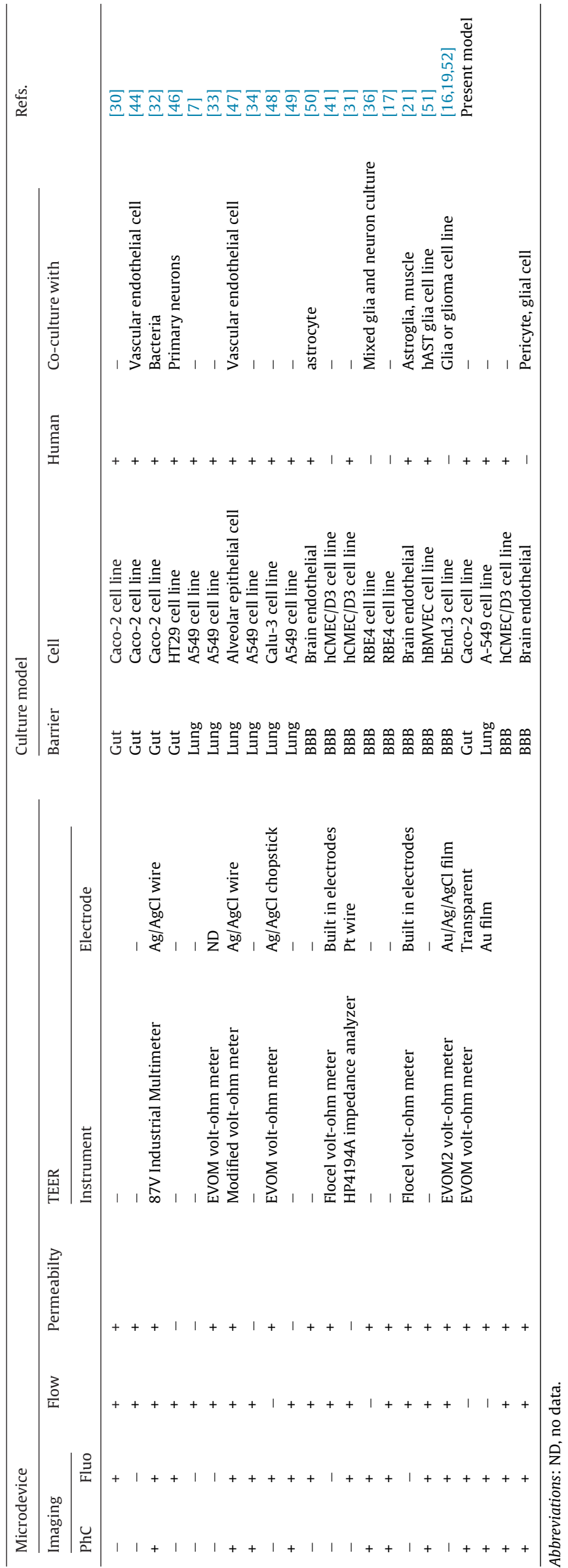


and under fluid flow. Integrated, complex microfluidic devices with co-culture systems were already described for gut [32] and lung [47] barrier models imitating micromovements, but no BBB model was established in an integrated chip with all the functions we described in the present manuscript.

\section{Conclusion and perspectives}

The aim of the study was to develop a general-purpose device that can be used to investigate multiple types of biological barriers as mono-, double- or triple cultures monitoring the electric conductivity and molecular permeability of the (co-)cultured cells under no flow or low flow conditions, at the same time allowing microscopic visualization of the whole membrane surface. The miniaturized chip was successfully used to model three different biological barriers with four types of cell cultures. Human intestinal epithelial, lung alveolar epithelial and brain endothelial cells grew all well in the new microdevice, and showed cell morphology and barrier functions similar to cultures on inserts. A similar co-culture of epithelial and endothelial cells may represent an anatomically more realistic model of the intestinal epithelium in the device and a novel approach to study oral absorption of drugs. The biochip was also suitable for modeling the BBB: formation of barriers was observed for both the brain endothelial cell line and the co-culture model. The triple primary co-culture blood-brain barrier model was established on a lab-on-a-chip device and investigated under fluid flow for the first time. The barrier-inducing effect of flow could be observed for the brain endothelial cell line, and further modification of the chip will permit the study of different flow and shear stress conditions. The device is expected to be a versatile tool for further examination of biological barriers, among them endothelial barrier functions under flow conditions.

\section{Conflict of interest}

There is a pending patent application on this topic. Authors declare that in connection to the present work there is no other potential conflict of interest.

\section{Acknowledgements}

This work was supported by the following grants: OTKA K-101821, OTKA NN-102624 and TÁMOP-4.2.2.A-11/1/KONV2012-0047. Fruzsina Walter received a fellowship for young researchers from the Hungarian Academy of Sciences. Hereby we acknowledge the help of Alexandra Bocsik and Dr. Lóránd Kiss for providing cell culture insert permeability and resistance data.

\section{Appendix A. Supplementary data}

Supplementary data associated with this article can be found, in the online version, at http://dx.doi.org/10.1016/j.snb.2015.07.110

\section{References}

[1] M.A. Deli, Potential use of tight junction modulators to reversibly open membraneous barriers and improve drug delivery, Biochim. Biophys. Acta 1788 (2009) 892-910.

[2] M.A. Deli, C.S. Ábrahám, Y. Kataoka, M. Niwa, Permeability studies on in vitro blood-brain barrier models: physiology, pathology, and pharmacology, Cell. Mol. Neurobiol. 25 (2005) 59-127.

[3] E. Hellinger, S. Veszelka, A.E. Tóth, F.R. Walter, Á. Kittel, M.L. Bakk, K. Tihanyi, V. Háda, S. Nakagawa, T.D. Duy, M. Niwa, M.A. Deli, M. Vastag, Comparison of brain capillary endothelial cell-based and epithelial (MDCK-MDR1, Caco-2, and VB-Caco-2) cell-based surrogate blood-brain barrier penetration models, Eur. J. Pharm. Biopharm. 82 (2012) 340-351.

[4] Q. Ramadan, H. Jafarpoorchekab, C. Huang, P. Silacci, S. Carrara, G. Koklü, J. Ghaye, J.J. Ramsden, C. Ruffert, G. Vergeres, M.A.M. Gijs, NutriChip: nutrition analysis meets microfluidics, Lab Chip 13 (2013) 196-203.
[5] L. Kiss, F.R. Walter, A. Bocsik, S. Veszelka, B. Ózsvári, L.G. Puskás, P. Szabó-Révész, M.A. Deli, Kinetic analysis of the toxicity of pharmaceutical excipients Cremophor EL and RH40 on endothelial and epithelial cells, J. Pharm. Sci. 102 (2013) 1173-1181.

[6] L. Kiss, É. Hellinger, A.M. Pilbat, Á. Kittel, Z. Török, A. Füredi, G. Szakács, S. Veszelka, P. Sipos, B. Ózsvári, L.G. Puskás, M. Vastag, P. Szabó-Révész, M.A. Deli, Sucrose esters increase drug penetration, but do not inhibit P-glycoprotein in Caco-2 intestinal epithelial cells, J. Pharm. Sci. 103 (2014) 3107-3119.

[7] S. Bakand, C. Winder, C. Khalil, A. Hayes, An experimental in vitro model for dynamic direct exposure of human cells to airbone contaminants, Toxicol. Lett. 165 (2006) 1-10.

[8] L. Wang, R. Taneja, W. Wang, L.J. Yao, R.A. Veldhuizen, S.E. Gill, D. Fortin, R. Inculet, R. Malthaner, S. Mehta, Human alveolar epithelial cells attenuate pulmonary microvascular endothelial permeability under septic conditions, PLoS ONE 8 (2013) e55311.

[9] B.B. Weksler, E.A. Subileau, N. Perrière, P. Charneau, K. Holloway, M. Leveque, H. Tricoire-Leignel, A. Nicotra, S. Bourdoulous, P. Turowski, D.K. Male, F. Roux J. Greenwood, I.A. Romero, P.O. Couraud, Blood-brain barrier-specific properties of a human adult brain endothelial cell line, FASEB J. 19 (2005) 1872-1874.

[10] B. Weksler, I.A. Romero, P.O. Couraud, The hCMEC/D3 cell line as a model of the human blood brain barrier, Fluids Barriers CNS 10 (2013) 16.

[11] A.E. Tóth, F.R. Walter, A. Bocsik, P. Sántha, S. Veszelka, L. Nagy, L.G. Puskás, P.O. Couraud, F. Takata, S. Dohgu, Y. Kataoka, M.A. Deli, Edaravone protects against methylglyoxal-induced barrier damage in human brain endothelial cells, PLoS ONE 9 (2014) e100152.

[12] M.A. Deli, Drug transport and the blood-brain barrier, in: K. Tihanyi, M. Vastag (Eds.), Solubility, Delivery and ADME Problems of Drugs and Drug-Candidates, Bentham Science Ltd., Washington, 2011, pp. 144-165.

[13] A.E. Tóth, S. Veszelka, S. Nakagawa, M. Niwa, M.A. Deli, Patented in vitro blood-brain barrier models in CNS drug discovery, Recent Pat. CNS Drug Discov. 6 (2011) 107-118.

[14] S. Nakagawa, M.A. Deli, S. Nakao, M. Honda, K. Hayashi, R. Nakaoke, Y. Kataoka, M. Niwa, Pericytes from brain microvessels strengthen the barrier integrity in primary cultures of rat brain endothelial cells, Cell. Mol. Neurobiol. 27 (2007) 687-694.

[15] S. Nakagawa, M.A. Deli, H. Kawaguchi, T. Shimizudani, T. Shimono, Á. Kittel, K. Tanaka, M. Niwa, A new blood-brain barrier model using primary rat brain endothelial cells, pericytes and astrocytes, Neurochem. Int. 54 (2009) 253-263.

[16] R. Booth, H. Kim, Characterization of a microfluidic in vitro model of the blood-brain barrier ( $\mu$ BBB), Lab Chip 12 (2012) 1784-1792.

[17] B. Prabhakarpandian, M.C. Shen, J.B. Nichols, I.R. Mills, M. Sidoryk-Wegrzynowicz, M. Aschner, K. Pant, SyM-BBB: a microfluidic Blood Brain Barrier model, Lab Chip 13 (2013) 1093-1101.

[18] W. Neuhaus, R. Lauer, S. Oelzant, U.P. Fringeli, G.F. Ecker, C.R. Noe, A novel flow based hollow-fiber blood-brain barrier in vitro model with immortalized cell line PBMEC/C1-2, J. Biotechnol. 125 (2006) 127-141.

[19] R. Booth, S. Noh, H. Kim, A multiple-channel, multiple-assay platform for characterization of full-range shear stress effects on vascular endothelial cells, Lab Chip 14 (2014) 1880-1890.

[20] S.K. Mahto, V. Charwat, P. Ertl, B. Rothen-Rutishauser, S.W. Rhee, J. Sznitman, Microfluidic platforms for advanced risk assessments of nanomaterials, Nanotoxicology 9 (2015) 381-395.

[21] L. Cucullo, M. Hossain, W. Tierney, D. Janigro, A new dynamic in vitro modular capillaries-venules modular system: cerebrovascular physiology in a box, BMC Neurosci. 14 (2013) 18.

[22] E. Hellinger, M.L. Bakk, P. Pócza, K. Tihanyi, M. Vastag, Drug penetration model of vinblastine-treated Caco-2 cultures, Eur. J. Pharm. Sci. 41 (2010) 96-106.

[23] S. Veszelka, M. Pásztói, A.E. Farkas, I. Krizbai, T.K. Ngo, M. Niwa, C.S. Ábrahám, M.A. Deli, Pentosan polysulfate protects brain endothelial cells against bacterial lipopolysaccharide-induced damages, Neurochem. Int. 50 (2007) 219-228.

[24] S. Veszelka, A.E. Tóth, F.R. Walter, Z. Datki, E. Mózes, L. Fülöp, Z. Bozsó, É. Hellinger, M. Vastag, B. Orsolits, Z. Környei, B. Penke, M.A. Deli, Docosahexaenoic acid reduces amyloid- $\beta$ induced toxicity in cells of the neurovascular unit, J. Alzheimers Dis. 36 (2013) 487-501.

[25] P. Hülper, S. Veszelka, F.R. Walter, H. Wolburg, P. Fallier-Becker, J. Piontek, I.E. Blasig, M. Lakomek, W. Kugler, M.A. Deli, Acute effects of short-chain alkylglycerols on blood-brain barrier properties of cultured brain endothelial cells, Br. J. Pharmacol. 169 (2013) 1561-1573.

[26] S. Liebner, M. Corada, T. Bangsow, J. Babbage, A. Taddei, C.J. Czupalla, M. Reis, A. Felici, H. Wolburg, M. Fruttiger, M.M. Taketo, H. von Melchner, K.H. Plate, H. Gerhardt, E. Dejana, Wnt/beta-catenin signaling controls development of the blood-brain barrier, J. Cell Biol. 183 (2008) 409-417.

[27] S.H. Ramirez, S. Fan, M. Zhang, A. Papugani, N. Reichenbach, H. Dykstra, A.J. Mercer, R.F. Tuma, Y. Persidsky, Inhibition of glycogen synthase kinase $3 \beta$ (GSK3 $\beta$ ) decreases inflammatory responses in brain endothelial cells, Am. J. Pathol. 176 (2010) 881-892.

[28] N. Perrière, P. Demeuse, E. Garcia, A. Regina, M. Debray, J.P. Andreux, P. Couvreur, J.M. Scherrmann, J. Temsamani, P.O. Couraud, M.A. Deli, F. Roux, Puromycin-based purification of rat brain capillary endothelial cell cultures. Effect on the expression of blood-brain barrier-specific properties, J. Neurochem. 93 (2005) 279-289. 
[29] E.A. Jähne, D.E. Eigenmann, M. Culot, R. Cecchelli, F.R. Walter, M.A. Deli, R. Tremmel, G. Fricker, M. Smiesko, M. Hamburger, M. Oufir, Development and validation of a LC-MS/MS method for assessment of an anti-inflammatory indolinone derivative by in vitro blood-brain barrier models, J. Pharm. Biomed. Anal. 98 (2014) 235-246

[30] Y. Imura, Y. Asano, K. Sato, E. Yoshimura, A microfluidic system to evaluate intestinal absorption, Anal. Sci. 25 (2009) 1403-1407.

[31] L.M. Griep, F. Wolbers, B. de Wagenaar, P.M. ter Braak, B.B. Weksler, I.A Romero, P.O. Couraud, I. Vermes, A.D. van der Meer, A. van den Berg, BBB on chip: microfluidic platform to mechanically and biomechanically modulate blood-brain barrier function, Biomed. Microdevices 15 (2013) $145-150$.

[32] H.J. Kim, D. Huh, G. Hamilton, D.E. Ingber, Human gut-on-a-chip inhabited by microbial flora that experiences intestinal peristalsis-like motions and flow, Lab Chip 12 (2012) 2164-2165.

[33] D.D. Nalayanda, C. Puleo, W.B. Fulton, L.M. Sharpe, T.H. Wang, F. Abdullah, An open-access microfluidic model for lung-specific functional studies at an air-liquid interface, Biomed. Microdevices 11 (2009) 1081-1089.

[34] S.H. Kim, S.M. Hwang, J.M. Lee, J.H. Kang, I.Y. Chung, B.G. Chung, Epithelial-to-mesenchymal transition of human lung alveolar epithelial cells in a microfluidic gradient device, Electrophoresis 34 (2013) 441-447.

[35] K.L. Sellgren, E.J. Butala, B.P. Gilmour, S.H. Randell, S. Grego, A biomimetic multicellular model of the airways using primary human cells, Lab Chip 14 (2014) 3349-3358.

[36] A.K. Achyuta, A.J. Conway, R.B. Crouse, E.C. Bannister, R.N. Lee, C.P. Katnik, A.A Behensky, J. Cuevas, S.S. Sundaram, A modular approach to create neurovascular unit-on-a-chip, Lab Chip 13 (2013) 542-553.

[37] O.F. Khan, M.V. Sefton, Endothelial cell behaviour within a microfluidic mimic of the flow channels of a modular tissue engineered construct, Biomed. Microdevices 13 (2011) 69-87.

[38] L.T. Chau, B.E. Rolfe, J.J. Cooper-White, A microdevice for the creation of patent, three-dimensional endothelial cell-based microcirculatory networks, Biomicrofluidics 5 (2011) 34115-3411514

[39] S. Kim, H. Lee, M. Chung, N.L. Jeon, A label-free DC impedance-based microcytometer for circulating rare cancer cell counting, Lab Chip 13 (2013) $1489-1500$

[40] C. Fede, I. Fortunati, L. Petrelli, D. Guidolin, R. De Caro, C. Ferrante, G. Albertin, An easy-to-handle microfluidic device suitable for immunohistochemical procedures in mammalian cells under flow conditions, Eur. J. Histochem. 58 (2014) 2360.

[41] L. Cucullo, P.O. Couraud, B. Weksler, I.A. Romero, M. Hossain, E. Rapp, D. Janigro, Immortalized human brain endothelial cells and flow-based vascular modeling: a marriage of convenience for rational neurovascular studies, J. Cereb. Blood Flow Metab. 28 (2008) 312-328.

[42] S. Veszelka, A. Kittel, M.A. Deli, Tools of modelling blood-brain barrier penetrability, in: K. Tihanyi, M. Vastag (Eds.), Solubility, Delivery and ADME Problems of Drugs and Drug-Candidates, Bentham Science Ltd., Washington, 2011, pp. 166-188.

[43] H.H. Sigurdsson, J. Kirch, C.M. Lehr, Mucus as a barrier to lipophilic drugs, Int J. Pharm. 453 (2013) 56-64

[44] J. Pusch, M. Votteler, S. Göhler, J. Engl, M. Hampel, H. Walles, K. Schenke-Layland, The physiological performance of a three-dimensional model that mimics the microenvironment of the small intestine, Biomaterials 32 (2011) 7469-7478

[45] F. Hervé, N. Ghinea, J.M. Scherrmann, CNS delivery via adsorptive transcytosis, AAPS J. 10 (2008) 455-472.

[46] C. Greß, M. Jeziorski, M. Saumer, K.H. Schäfer, Simulation of in-vivo-equivalent epithelial barriers using a micro fluidic device, Biomed. Microdevices 16 (2014) 191-198.

[47] D. Huh, B.D. Matthews, A. Mammoto, M. Montoya-Zavala, H.Y. Hsin, D.E. Ingber, A mechanosensitive transcriptional mechanism that controls angiogenesis, Science 328 (2010) 1662-1668.

[48] L. Bol, J.C. Galas, H. Hillaireau, I. Le Potier, V. Nicolas, A.M. Haghiri-Gosnet, E. Fattal, M. Taverna, A microdevice for parallelized pulmonary permeability studies, Biomed. Microdevices 16 (2014) 277-285.

[49] S.K. Mahto, J. Tenenbaum-Katan, A. Greenblum, B. Rothen-Rutishauser, J. Sznitman, Microfluidic shear stress-regulated surfactant secretion in alveolar epithelial type II cells in vitro, Am. J. Physiol. Lung Cell Mol. Physiol. 306 (2014) L672-L683.

[50] V. Siddharthan, Y.V. Kim, S. Liu, K.S. Kim, Human astrocytes/astrocyte-conditioned medium and shear stress enhance the barrier properties of human brain microvascular endothelial cells, Brain Res. 1147 (2007) 39-50.

[51] Y Takeshita, B. Obermeier, A Cotleur, Y Sano, T. Kanda, R.M. Ransohoff, An in vitro blood-brain barrier model combining shear stress and endothelial cell/astrocyte co-culture, J. Neurosci. Methods 232 (2014) 165-172.
[52] R. Booth, H. Kim, Permeability analysis of neuroactive drugs through a dynamic microfluidic in vitro blood-brain barrier model, Ann. Biomed. Eng. 42 (2014) 2379-2391.

\section{Biographies}

Fruzsina R. Walter obtained her MSc in biology at the University of Szeged, Hungary in 2010. She conducts her PhD studies (delivery of drugs to the central nervous system by opening the blood brain barrier) at the Biological Research Centre, Szeged, Hungary. She is currently a junior research associate in the Institute of Biophysics of the Centre. Her present works include the development and study of novel culture models of the blood-brain and other barriers using microfluidic devices. She received several prizes and recognitions for her achievements as a research student.

Sándor Valkai is a staff scientist of the Institute of Biophysics, Biological Research Center of the Hungarian Academy of Sciences. He received his MS diploma in physics in 1995 at József Attila University Szeged, Hungary. He got a PhD degree at the Veszprém University, Veszprém, Hungary in 1999. He was a post doc at Bar-Ilan University, Ramat Gan, Israel between 1999 and 2001. From 2002, he deals with integrated optics and nanotechnology in BRC, Szeged. He is co-author of several scientific papers and patents.

András Kincses is a PhD student of the University of Szeged, Hungary, working in the Institute of Biophysics, Biological Research Centre, under the supervision of A.D. His research interest is connected mainly with elaborating alternative electrophysiological techniques for measurement of electric signals associated to cell physiological processes. As a visiting student, he has been invited to the Max Planck Institute of Biophysics, Frankfurt am Main, Germany, and to the Technical University of Denmark, Copenhagen. He is the first author or co-author of several scientific publications.

András Petneházi and Tamás Czeller have prepared their BSc theses in the Institute of Biophysics, BRC, concerning the biological application of various lab-on-a-chip devices. The diploma works were carried out under the supervision of M.D. and A.D., in the framework of the undergraduate degree program "Molecular Bionics" of the University of Szeged.

Szilvia Veszelka is a postdoctoral research associate at the Biological Research Centre, Szeged, Hungary. She received both her MSc in 2003 and PhD degree in 2007 at the University of Szeged, Hungary. After obtaining her PhD thesis (protection against blood-brain barrier damages in pathological conditions) she started a new project on drug targeting to brain by different nanoparticles decorated with ligands of solute carriers or transporters. She was awarded two research grants for young investigators from Gedeon Richter Plc., Hungary. Her present studies are funded by a postdoctoral research grant from the Hungarian Scientific Research Fund.

Pál Ormos is the director general of the Biological Research Center of the Hungarian Academy of Sciences. He has MSc (1975) and $\mathrm{PhD}(1982)$ in physics from Jozsef Attila University Szeged. He is an ordinary member of the Hungarian Academy of Sciences (1994). P. Ormos is honorary president of the Hungarian Biophysical Society. Between 2002 and 2005 he served as vice president of IUPAP (International Union of Pure and Applied Physics). P. Ormos's research is focused on single particle observation, optical micromanipulation and nanobiotechnology. He is author or co-author of $\mathrm{ca}$. 100 publications and there are over 4000 citations to them. He is an elected Fellow of the American Physical Society.

Mária A. Deli is a group leader and scientific advisor at the Biological Research Centre, Szeged, Hungary, a Center of Excellence of the European Union. She graduated as an $\mathrm{MD}$ and received a $\mathrm{PhD}$ degree from the University of Szeged. Her main research interests include culture models of biological barriers, blood-brain barrier protection in pathologies like Alzheimer's disease and diabetes, drug targeting to brain by different strategies, blood-brain barrier models for central nervous system drug testing. She has published 81 PubMed indexed research articles including 9 reviews, and 12 book chapters (independent citations over 2400, Hirsch index: 31 ). Present research team includes 3 postdoctoral researchers, $3 \mathrm{PhD}$ students and 8 undergraduate students.

András Dér is a group leader and scientific advisor of the Institute of Biophysics, Biological Research Center of the Hungarian Academy of Sciences, Szeged, Hungary. He received an MS diploma in physics in 1980 at József Attila University Szeged, Hungary, a CSc (PhD) and a DSC degree from the Hungarian Academy of Sciences in 1988 and 1999, respectively. He has been the co-president of the Biophysics Committee of the Hung. Acad. Sci., and the vice president of the Hungarian Biophysical Society. His major research area is protein dynamics and bioelectronics. Togethe with his colleagues, he is named as inventor on several granted and pending patents about the photonic application of biomaterials. 